\title{
A Review On Regulatory Requirements To Prevent Counterfeit Drugs In India
}

\author{
Mourya Mamtashanti*, Jadav Rahul, Thummar Kashyap \\ Graduate School of Pharmacy, Gujarat Technological University, Gandhinagar, Gujarat, INDIA.
}

\begin{abstract}
Counterfeit drugs are a serious issue nowadays, which has been burdening for developing countries and has a significant impact on the health of people. The Indian drug regulatory agency has published the details of the counterfeited products found in recent years, the data indicates an alarming situation in the country to achieve a well-becoming level of attention between policymakers, researchers and the pharmaceutical industry. The present paper shows a thorough review of relevant and incidental literature from different agencies to reach the counterfeiting of drugs, its type, statistics, incidents and deficiency in Indian regulation. Different country regulations like U.S, Europe and Canada have also discussed in comparison with Indian regulation which shows that how India should adopt the technologies present in other countries to combat counterfeit medicine. Different technologies exist for prevention for counterfeitings of drugs like
\end{abstract}

overt, covert and trace and track technologies; serialization and blockchain In this article, the main focus is given on serialization and blockchain which will help from entering the counterfeit drugs into the supply chain because of unique code put on each box of drugs to trace them.

Key words: Counterfeit, Falsified, Pharmaceutical, Serialization, Blockchain SFFC.

\section{Correspondence}

Ms. Mourya Mamtashanti Shambhunath, M. Pharm

Graduate School of Pharmacy, Gujarat Technological University, Sector - 26 , Gandhinagar - 382028, Gujarat, INDIA.

Phone no: +91 7600785706

Email: mamtamourya1993@yahoo.com

DOI: 10.5330/ijpi.2020.3.47

\section{INTRODUCTION}

Drug counterfeiting has become a problem of huge scale globally which has increased the level of attention between researchers, managers and policymakers. The counterfeiting of drugs has grown as a serious issue as the health of the people who consume such medicine may be at risk. Counterfeit medicines are those which may contain no active pharmaceutical ingredient (API) at all, wrong amounts of the correct API, wrong APIs, sole or in mixtures, API in the right quantity but with counterfeit packing, labeling and patient information leaflet (PIL). ${ }^{1,2}$ The spurious/falsy labeled/falsified/counterfeit (SFFC) is the similar terms used by different regulatory authorities to indicate poor quality of medicines which can cause treatment failure or death also.

Drugs need to safe, efficacious and need to prevent disease because they play important role in saving lives, prevent diseases and healthy of people. ${ }^{3}$ The problem of counterfeit medicines has grown in both developed and developing nations. The majority of developed countries with effective regulations and market control i.e. USA, EU, Australia, Canada, Japan and New Zealand at present have a low fraction of counterfeit medicines (i.e. $<1 \%$ of market value). However, indications point to a rise in the incidence of counterfeit medicines yet in developed countries.

More than $30 \%$ of the drugs are counterfeit sold in the various parts of Africa, Latin, Amaerica and Asia. In general, a reasonable estimation is between 10 and $30 \%$ of the total market share in the developing nations (Figure 1). Soviet Republics have 20\% value of counterfeit medicines in whole market, falling into the developing country range. The $50 \%$ of medicines bought over the internet from websites that hide their actual physical address are found to be counterfeit. Theoretically, all patients are at risk, yet there might be differences based on the countries. ${ }^{4}$

The market value of counterfeit medicine is also increasing due to the imbalance in supply and demand. Due to more demand for drugs and the less supply, the counterfeit medicines find their way into the market. The biggest producer of counterfeit drugs is thus found to be in the Asian region where the issue of counterfeit medicines is also very high in the domestic market.

\section{Types of counterfeits}

Counterfeit medicines are of different types. They are categorized into medicines, active pharmaceutical ingredients (API), packaging and false documentation as shown in Table 1. These counterfeit or spurious medicines leads to the serious effect of public health as the public are not aware of it. ${ }^{6}$

The counterfeits can be broken into these six categories and the counterfeit drugs with percentage estimation in the market found by WHO were presented in Figure 2.

According to WHO $60 \%$ of the drugs are a counterfeited which includes antibiotics, hormones, analgesics, steroids and anti-histamines. Costly, prescription drugs used in the case of AIDS or cancer treatment, are particularly profitable for uncertain businesses. Antibiotics are the most usually counterfeited drugs, mainly in low-income countries where medicines are costly for many citizens. ${ }^{8}$ Cardiovascular drugs are more counterfeited because heart patients are so in a large amount. This way many medicines are categorized and mentioned in (Figure 3) which shows that the percentage of counterfeited drugs category wise.

\section{Factors Facilitating Counterfeiting of Medicines. ${ }^{9}$}

There are various factors which contribute to facilitating the counterfeit medicines. All of these factors should be accurately identified which can help the government to determine the problem of counterfeiting so that effective regulations can be formed to prevent the counterfeiting of 
drugs. The various factors which may be applicable in the counterfeiting of medicines are as follows:

- Lack of legislation

- Deficient national drug regulatory authority

- Lack of enforcement of existing legislation

- Lenient or lack of penal sanctions

- Corruption and conflict of interest

- Transactions involving many intermediaries

- Demand exceeding supply

- High prices

- Sophistication in clandestine drug manufacture

- Inefficient cooperation between stakeholders

- Lack of regulation by exporting countries and within free trade zones

Impact of Counterfeit drugs. ${ }^{10}$

WHO determines the public health and socio-economic impact of counterfeit drugs

\section{socio-economic impact}

- Lost productivity

- Lost income

- Lack of social morbidness

- Increased poverty

\section{Economic Impact}

- Economic loss

- Wasted resources

- Increased out of pocket spending

Health factors

- Loss of confidence

- Increased death rate

- Higher disease prevalence, anti-microbial resistance. ${ }^{10}$

\section{COUNTERFEIT INCIDENT REGIONS OF THE WORLDS}

According to the pharmaceutical security institute, incidents have been analyzed concerning seven regions of the world. Out of 4,405 pharmaceutical crime incidents, the Institute found:

The Figure 4 shows that:

- In the total worldwide incident has increased to twenty-six percent increase $(+26 \%)$.

- Asia is at the 2 nd rank after north America. This chart shows that the incidents rate has been increasing with a high rate in India. ${ }^{11}$

\section{INDIA'S STATUS ON COUNTERFEIT DRUGS}

The Indian pharma industry is the third-largest in the world in terms of volume, accounting for 10 percent of the world's production. With exports to more than 200 countries, India is the world leader in the production of generic drugs and vaccines. India is also a largest source of counterfeit medicines in terms of export of such fake medicines. Many reports show that most of the counterfeit medicines captured are tracked down to find the source and India is the big source of counterfeit medicines followed by China. The study conducted by WHO in 2017 shows that the number of counterfeit medicines in India was found to be 20 to $30 \%$ based on the collection and evaluation of the samples from all over India. ${ }^{10}$ India lacks the proper regulations for the manufacturing and distribution of drugs and also other factors which influence the counterfeit medicines production is the fact that no major action is taken for those found guilty and the penalty is very low as compared to the profit. Lately, Guidelines has been developed for taking action on samples of drugs which is declared spurious or not of standard according to The Drugs and Cosmetics (Amendment) Act and 10 years imprisonment for the same.The amount of people who are affected by the use of such medicines is also increasing and necessary action needs to be taken for the prevention of counterfeit medicines. The number of people dying of counterfeit drugs is only estimated and an exact figure is not available because the amount of counterfeit drugs in the market is not detected effectively in most of the emerging markets and due to it the fake medicines finds a place into the market where these counterfeit drugs are sold which causes harm to the person who consumes such counterfeit drugs. ${ }^{12}$

\section{SFFC OR NSQ DRUGS IN INDIA}

Poor quality drugs spurious/falsely-labeled/falsified/counterfeit (SFFC) or Not of Standard Quality (NSQ) medicines can cause the death of the patient or treatment failure. ${ }^{13}$ Approximately $12-25 \%$ of the drugs distributed from India are contaminated, substandard and counterfeit and India as it is the vast manufacturer of generic drugs. Being the world's largest generic manufacturer, India could be major contributors to the spurious drugs along with china.

Drug and cosmetic acts categorized drugs into various categorized, misbranded spurious and adulterated. With the 2008 amendment of the D and C act, Indian drug regulatory authority that is Central Drugs Standard Control Organization (CDSCO) has categorized not of standard quality (NSQ) products in three categories A, B and C that helps categorize the products during quality evaluation as shown in Table 2. ${ }^{14,15}$ Several samples had been tested in past years and divided into a different category. These samples show that amount of samples tested and the category of spurious drug is divided i.e. spurious and not of standard quality drugs as shown in Table 3.

\section{REGULATIONS IN INDIA}

\section{In India, counterfeit drugs are seen under the Drug and} Cosmetics Act 1940 and Rules 1945.

- Guidelines has been declared for taking Action on Samples of Drugs which Declared Spurious or Not of Standard Quality with enhanced penalties.

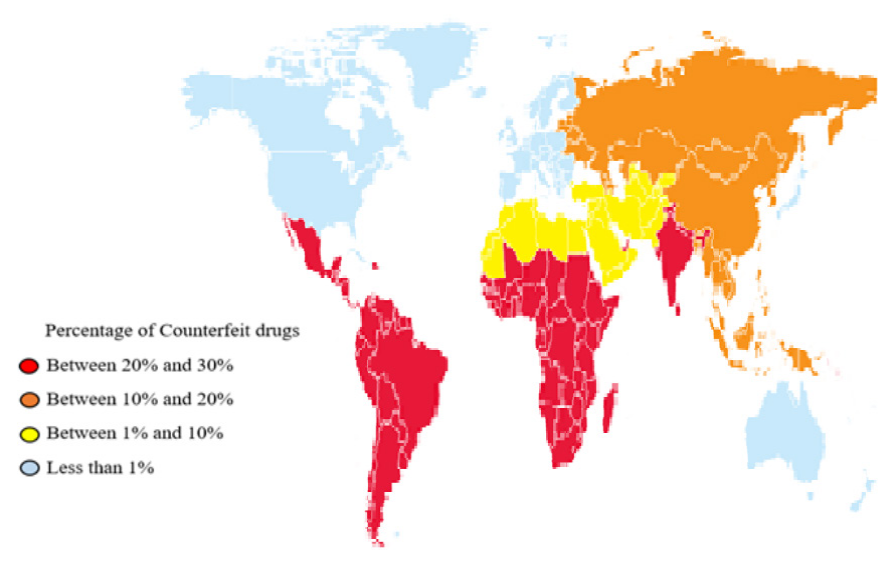

Figure 1: Global Repartition of Counterfeiting Medicines. ${ }^{5}$ 


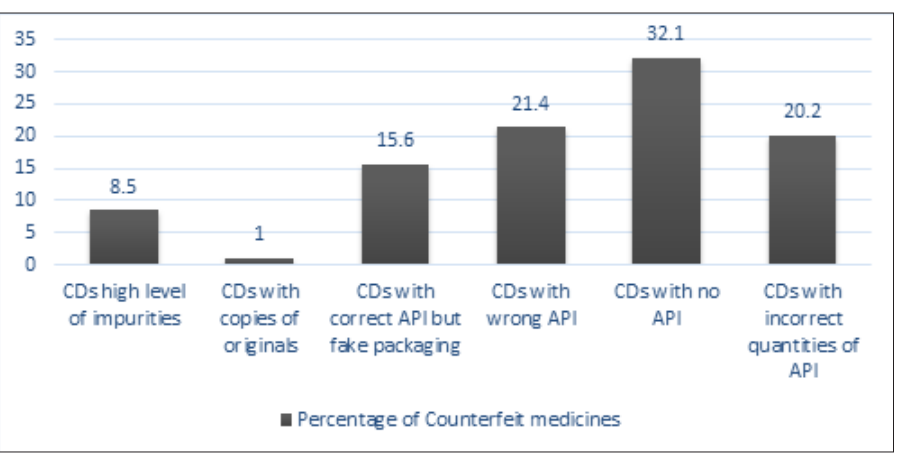

Figure 2: Counterfeit Drugs (CDs) found with Percentage estimation in the market. $^{7}$

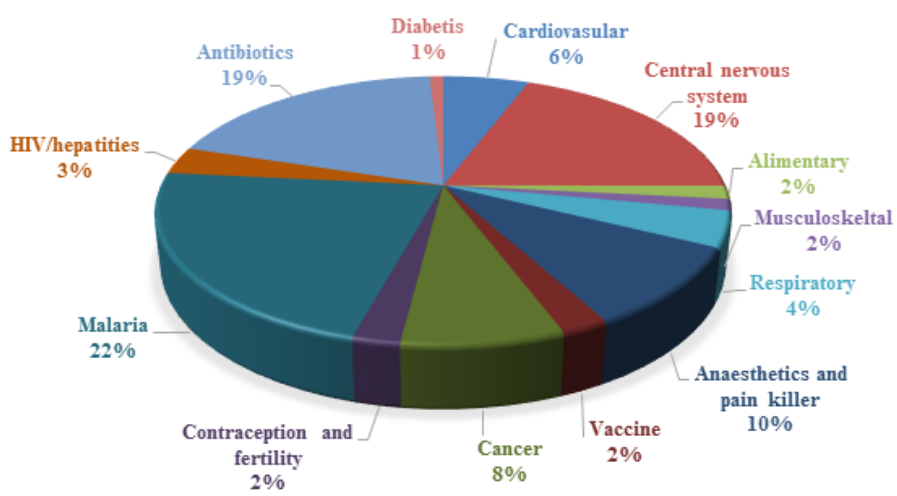

Figure 3: Counterfeit drugs found by its therapeutic class.

- $\quad$ Reward Scheme for whistle-blowers in the fight against the menace of spurious or fake drugs, cosmetics and medical devices.

- $\quad$ Procedure for Implementation of the Track and Trace system for the export of drug formulations as shown in Table $4 .{ }^{17}$

\section{Deficiency in Indian Regulation}

- According to research from the WHO study, 1 in 10 medicinal products are counterfeited. Since 2013, 1500 cases had been reported so, before 2013 many cases were there that was unreported. So according to the regulation by the Director-General of Foreign Trade (DGFT), there should be a barcoding system for drug exporting out of the country.

- The manufacturers are also required to upload the information about the drug product on the central server where the tracking of the product is possible.

- So, this main deficiency in the Indian regulation where the regulations are framed for the export of products in which barcodes are to be added and the tracking of the product can be done. ${ }^{20}$

\section{TECHNIQUES TO PREVENT COUNTERFEIT MEDICINES.}

There are several techniques available in the market to prevent the drug from counterfeiting. But here two techniques have been discussed which can be used in the pharma sector as the counterfeiting has been increasing day by day, so these two techniques can have brought a lot of changes in the prevention of counterfeiting of drugs. Indian healthcare sectors should also need to adopt this technique. ${ }^{21,22}$

\section{Serialization}

Serialization is a unique anti-counterfeit technique. As the name itself, a unique code will be alloted to each drug product which will remain

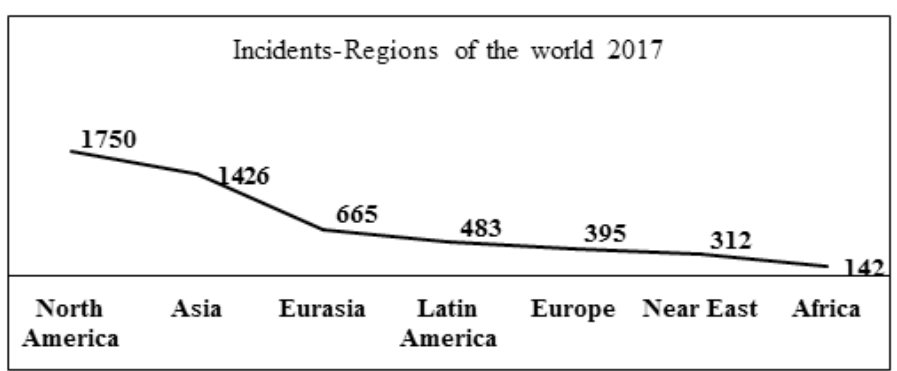

Figure 4: Incident -regions of the world's. ${ }^{11}$

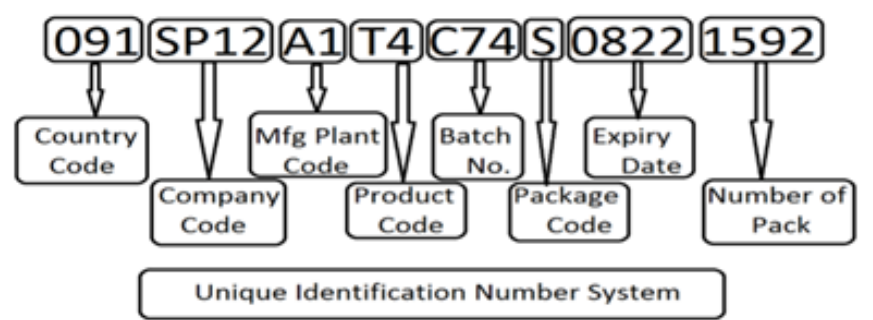

Figure 5: Unique Identification Number (UIN).

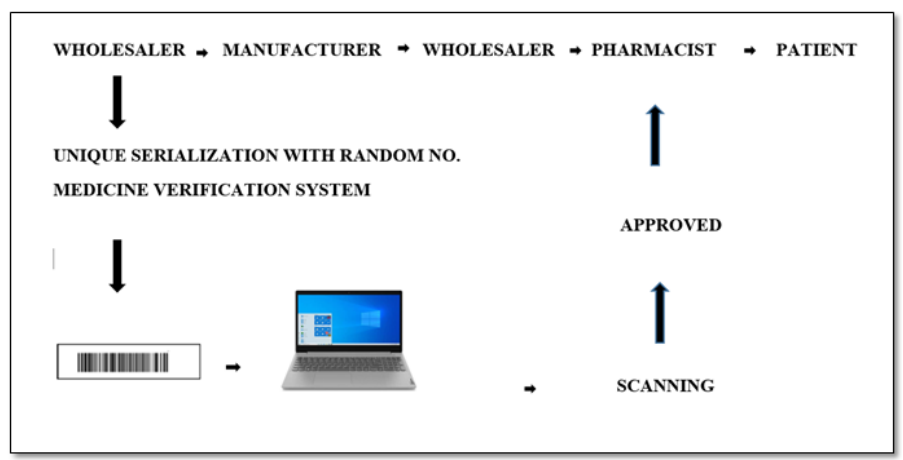

Figure 6: Serialization of Pharmaceutical product. ${ }^{25}$

throughout drug supply until its consumption. So, it will be easy to identify the product and it can easily access all the information stored in a secure database as shown in Figure $5 .^{23}$

Track and trace may not be immune to copying or falsification are not easy but if the random serial number is or non-sequential numbering is assign then the sequence is not predictable. ${ }^{24}$

A unique identification number is easily visible on a pack and can easily be verified by customers telephone, internet links to the database.

The Unique Identification Number should comprise of Country Code, Company Code, Manufacturing, Plant Code, Product Code, Batch Number, Package Code, Expiry Date and Number of packs.

When all the codes are combined a unique code will be generated which will be a 23-character code for a particular pack of a drug product. After assigning UIN to the drug product it will pass through a supply chain and verified immediately if there is any doubt the drug product at any stage of the supply chain. This is the (Figure 6) mentioned below showing how serialization works for a pharmaceutical product.

\section{Benefits of Pharmaceutical Serialization ${ }^{26}$}

Fighting against Counterfeit drugs

Smoother refunds and recalls 


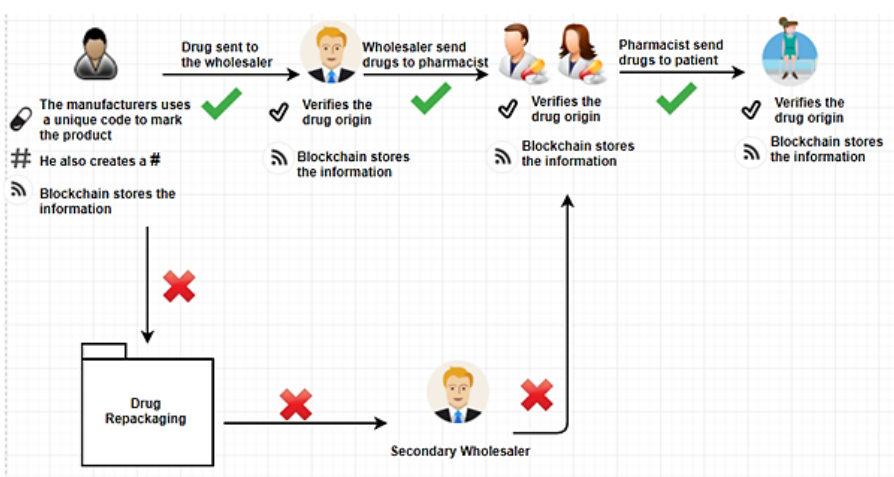

Table 2: Category of Not of standard quality (NSQ).$^{14}$

\begin{tabular}{cc} 
Category & Not of standard quality (NSQ) \\
\hline A & $\begin{array}{c}\text { Spurious and adulterated drug products (No API, containing } \\
\text { filthy material }\end{array}$ \\
B & $\begin{array}{c}\text { Substandard drugs (Drugs failing disintegration and dissolution } \\
\text { test) }\end{array}$ \\
C & $\begin{array}{c}\text { Minor defects like emulsion cracking, change in formulation } \\
\text { color, mall variation in net content, sedimentation in a clear } \\
\text { liquid preparation, failing of eight variation test, spot or } \\
\text { discoloration on the product, uneven coating, presence of } \\
\end{array}$ \\
& foreign matter and labeling errors.
\end{tabular}

Figure 7: Blockchain process. ${ }^{28}$

Table 1: Different types of counterfeits found on the market. ${ }^{6}$

\begin{tabular}{|c|c|c|c|}
\hline $\begin{array}{l}\text { S } \\
\text { No. }\end{array}$ & Counterfeit & Types of counterfeit & Characteristics \\
\hline \multirow[t]{5}{*}{1} & Medicines & No API & $\begin{array}{l}\text { Brand medicines for } \\
\text { industrialized areas }\end{array}$ \\
\hline & & Wrong API & $\begin{array}{c}\text { Generics for } \\
\text { developing countries }\end{array}$ \\
\hline & & Right API, wrong dosage & $\begin{array}{l}\text { Lifestyle medicines } \\
\text { for industrialized } \\
\text { countries Sold via } \\
\text { internet }\end{array}$ \\
\hline & & Very good copy & $\begin{array}{c}\text { Repackaged with fake } \\
\text { dates }\end{array}$ \\
\hline & & $\begin{array}{l}\text { Expired genuine } \\
\text { medicines }\end{array}$ & $\begin{array}{l}\text { Containing reused } \\
\text { components }\end{array}$ \\
\hline \multirow[t]{3}{*}{2} & APIs & $\begin{array}{l}\text { An unauthorized API sold } \\
\text { as an authorized API }\end{array}$ & - \\
\hline & & $\begin{array}{l}\text { API manufactured by } \\
\text { another process }\end{array}$ & - \\
\hline & & $\begin{array}{l}\text { API produced by } \\
\text { unregistered firms and } \\
\text { fraudulently mislabeled }\end{array}$ & - \\
\hline \multirow[t]{2}{*}{3} & Medical devices & Old repackaged material & - \\
\hline & & $\begin{array}{l}\text { Inferior-quality material } \\
\text { fraudulently mislabeled }\end{array}$ & - \\
\hline 4 & Packaging & $\begin{array}{l}\text { Copy of the genuine } \\
\text { packaging }\end{array}$ & $\begin{array}{l}\text { Updated fake data } \\
\text { Items sometimes } \\
\text { non-existent }\end{array}$ \\
\hline 5 & Documentation & $\begin{array}{c}\text { Documentation } \\
\text { False documentation } \\
\text { (Certificate of Suitability, } \\
\text { import status, etc.) }\end{array}$ & - \\
\hline
\end{tabular}

- Product authentication

- Product verification

- Improve shelf-life management

\section{Blockchain}

Blockchain is also a new technique for the anti-counterfeiting of drug products. It can be easily with all network participants who are directly involved in the drug supply. Blockchain is a reorganized record so because of its nature, mathematically, its records can not be modifying. It can

Table 3: Recent data of Number of Samples Tested, Found Substandard / Spurious from 2019 to 2020. ${ }^{16}$

\begin{tabular}{cccccc}
\hline Year & $\begin{array}{c}\text { Total } \\
\text { number } \\
\text { of } \\
\text { samples } \\
\text { tested }\end{array}$ & $\begin{array}{c}\text { Standard } \\
\text { Quality }\end{array}$ & $\begin{array}{c}\text { Not of } \\
\text { Standard } \\
\text { Quality }\end{array}$ & Spurious & Misbranded \\
\hline $\begin{array}{c}\text { August } \\
2019\end{array}$ & 951 & 923 & 28 & Nil & Nil \\
$\begin{array}{c}\text { September } \\
2019\end{array}$ & 1134 & 1113 & 21 & Nil & Nil \\
$\begin{array}{c}\text { October } \\
2019\end{array}$ & 1163 & 1127 & 36 & 0 & 0 \\
$\begin{array}{c}\text { November } \\
2019\end{array}$ & 1158 & 1121 & 37 & 0 & 0 \\
$\begin{array}{c}\text { December } \\
2019\end{array}$ & 1336 & 1286 & 49 & 1 & 0 \\
$\begin{array}{c}\text { January } \\
2020\end{array}$ & 1171 & 1143 & 34 & Nil & Nil \\
$\begin{array}{c}\text { February } \\
2020\end{array}$ & 1271 & 1233 & 38 & 0 & 0 \\
\hline
\end{tabular}

Table 4: Regulations of India at Central and State level for drugs. ${ }^{18,19}$

\begin{tabular}{|c|c|c|}
\hline Sr. No. & At the Central Level & At the State Level \\
\hline 1. & $\begin{array}{c}\text { Giving Approval to new } \\
\text { drugs }\end{array}$ & $\begin{array}{l}\text { Licensing of drug manufacturing } \\
\text { establishments and sales premises }\end{array}$ \\
\hline 2. & $\begin{array}{l}\text { Permission to conduct } \\
\text { clinical trials }\end{array}$ & Inspecting licensed premises \\
\hline 3. & $\begin{array}{l}\text { Laying down the standards } \\
\text { for drugs, cosmetics, } \\
\text { diagnostics and devices } \\
\text { and updating Indian } \\
\text { Pharmacopoeia }\end{array}$ & $\begin{array}{l}\text { Drawing samples for tests and } \\
\text { monitoring the quality of drugs } \\
\text { and cosmetics in the state. }\end{array}$ \\
\hline 4. & $\begin{array}{l}\text { Approving licenses as the } \\
\text { Central License Approving } \\
\text { Authority (CLAA) for the } \\
\text { manufacture of drugs. }\end{array}$ & $\begin{array}{l}\text { Taking appropriate action like } \\
\text { suspension or cancellation of } \\
\text { licenses. }\end{array}$ \\
\hline
\end{tabular}

only have achieved by the using cryptographic algorithms. Its structure is immutable and in strict order. Immutability is implemented by using a hash, a digital fingerprinting data. So, every block has reference to a previous hence it gives strict order Since blockchain is timestamped and immutable, so it can't be fraudulent by drug traffickers as shown in Figure $7 .^{27}$ 
Mamtashanti, et al.: Prevention of Counterfeit Drugs in India

Table 5: Comparison of regulations of different countries with India for counterfeited medicines.

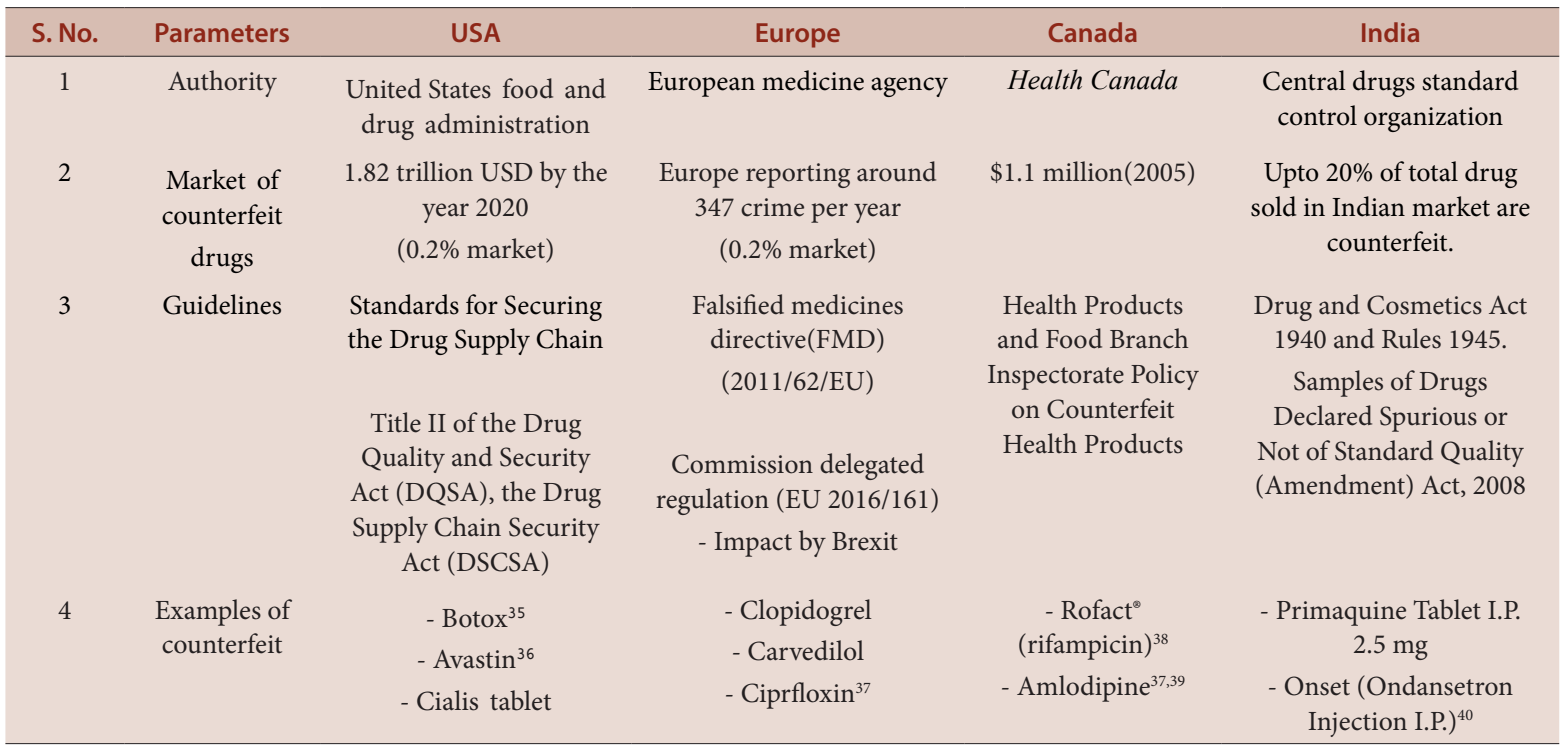

\section{There are two types of blockchains}

- Public

- Private

The health care companies register their product in a private blockchain system to ensure the quality and reliability of the products. The private blockchain is handled by the central entity and the supplier or manufacturer has permission only to access blockchain to proves its authenticity. Once the drug is manufactured and then it is transferred to the vendor all the operational data will be recorded and stored in the blockchain. The complete process of drug supply is very easy and can be check at any time. Blockchain is designed to keep health care data secure and transparent. ${ }^{29}$

Indian Blockchain technology market growth in healthcare is $81.9 \%$ over the estimation period. Due to the rise in the clinical exchange data, the security of data has resulted in increase privacy, security and confidentiality of health data. The use of blockchain technology in health insurance claims management will expand the market growth soon. ${ }^{30}$

\section{Advantages}

- All participants are involved in the pharmaceutical supply chain

- Blockchain is unchangeableand time-stamped

- All products can register in blockchain for authenticity

- It cannot be fraudulent by drug traffickers

- All data will be secured and transparent

- The market of blockchain in India is growing in the healthcare market

- Drug supply complete process is easy

\section{COMPARISON OF REGULATORY REQUIREMENTS OF DIFFERENT COUNTRIES WITH INDIA FOR COUNTERFEITED MEDICINES. ${ }^{31-34}$}

Regulations of India for counterfeit medicines were compared with different countries like the United States of America (USA), Europe and Canada as shown in Table 5..$^{31-34}$

\section{CONCLUSION}

Poor quality drugs affect the health of the public. Spurious or counterfeit drugs are involved in both generic and branded products of every category throughout the world, which is increasing its roots and creating a threat to public health. Counterfeiting leads by various reasons like high prices, competition between sponsors, weak regulatory authorities, employment and market transparency. India has categorized drugs of not so standard quality into various three categories A, B and C. India is taking measures and stringent penalties for the poor quality of the drugs and ensuing the public health.

There are several techniques available in the market to prevent the drug from counterfeiting. Deficiency in Indian regulation has been discussed and steps and techniques should also have been discussed but here two techniques have been discussed which can be used in pharma sector as the counterfeiting has been increasing day by day, so these two techniques can have brought a lot of changes in the prevention of counterfeiting of drugs. Serialization and blockchain is a very effective way of preventing counterfeit drugs from entering the supply chain. India has been using the serialization method for the pharmaceutical products that are exported from India. If the serialization and blockchain are introduced for the product that is sold in India, then the number of counterfeit drugs can be drastically reduced and the safety of the patients who consume such a product can be ensured Indian healthcare sectors should also need to adopt this technique. Regulations of India for counterfeit medicines is compared with different countries like the USA, Europe and Canada. It is now the time to explore this matter more vigorously in the times to come to safeguard the interests of the patient at large.

\section{ACKNOWLEDGEMENT}

The authors would like to thanks Mr. Nirav Choksi, Senior General Manager, Zydus Cadila Healthcare Ltd., Ahmedabad - 382210, Gujarat for technical support

\section{CONFLICT OF INTEREST}

The authors declare that they have no conflict of interest.

\section{ABBREVIATIONS}

API: Active pharmaceutical ingredient; CDSCO: Central Drugs Standard Control Organization; CLAA: Central license approving authority; 
DGFT: Director-General of Foreign Trade; EMA: European medicine agency; NSQ: Not of standard quality; PIL: Patient information leaflet; SFFC: Spurious/Falsy labelled/Falsified/Counterfeit; UIN: Unique Identification Number; USA: United State of America.

\section{REFERENCES}

1. WHO. Preliminary draft survey on national legislation on "Counterfeit Medicines. 2010. [cited Oct 2019]. Available from: http://www.who.int/medicines/ services/counterfeit/WHO_ACM_Report.pdf.

2. WHO. Third IMPACT General Meeting 3-5. 2008. [cited Nov 2019]. Available from: http://www.who.int/medicines/services/expertcommittees/pharmprep/ WHO-ACM-3IMPACTSurveyDataCollectionToolReport.pdf.

3. Moran B. Cracking Down on Counterfeit Drugs. 2019. [cited Nov 2019]. Available from: http://www.pbs.org/wgbh/nova/next/body/uncoveringcounterfeitmedicines/.

4. FIP combats falsified and substandard medicines. International Pharmaceutical Federation. 2019. [cited Nov 2019]. Available from: https://fip.org/counterfeit_medicines.

5. Wilfried Roge. 2019. [cited Sep 2019]. Available from: https://ec.europa.eu/internal_market/indprop/docs/conf2008/wilfried_roge_en.pdf.

6. Klara D, RoggoY, Margot P. Understanding and fighting the medicine counterfeit market. Elsevier. 2014;87:167-75.

7. Nursing School Hub.com. The effect of counterfeit medication. 2020. [cited Sep 2020]. Available from: https://www.nursingschoolhub.com/effects-counterfeitmedication/

8. WHO"Essential medicnes and health product information portal. 2018. https:// apps.who.int/medicinedocs/en/d/Jwhozip16e/8.3.html.

9. WHO. Guidelines for the development of measures to combat counterfeit drugs. 2019. [cited Dec 2019]. Available from: http://www.who.int/medicines/ publications/counterfeitguidelines/en/.

10. WHO. A study on the public health and socioeconomic impact of substandard and falsified medical products. 2019. [cited Aug 2019]. Available from: http:// www.who.int/medicines/regulation/ssffc/publications/se-study-sf/en/.

11. Pharmaceutical security institute Incidents Region of the world. 2020. [cited Feb 2020]. Available from: https://www.psi-inc.org/geographic-distribution.

12. Times of India. Counterfeit medicines kill more people than terror: $\mathrm{CBI}$ chief 2015. [cited Nov 2019]. Available from:https://timesofindia.indiatimes.com/ india/Counterfeit-medicines-kill-more-people-than-terror-CBI-chief/articleshow/47808588.cms.

13. WHO. Medicines: Spurious/falsely-labeled/falsified/counterfeit (SFFC) medicines. 2013. http://www.who.int/mediacentre/factsheets/fs275/en/index.html.

14. Khan RKK. Current Scenario of Spurious and Substandard Medicines in India: A Systematic Review. Indian Journal of Pharmaceutical science. 2015;77(1):2-7.

15. Khalid MAS. Global Perspective of Regulatory Systems to Spurious, Adullterated and not of Standard Quality Drugs and to recommend measures for their effective eradication in the Indian Regulatory System. Pharma Times. 2018;50:12.

16. CDSCO. Drug alert of drugs not of standard quality. 2020. [Internet]. [cited March 2020]. Available from: https://cdsco.gov.in/opencms/opencms/en/Notifications/Alerts/.

17. Pharmaceutical Security Institute. 2020. [cited Oct 2019]. Available from: http:// www.psi-inc.org/counterfeitSituation.cfm.

18. Sagar BPS, Aklavya S. Counterfeit, fake, spurious drugs. Health Administrator. 2015;65-73.

19. Madhur GDMS, Singh GN, Alireza K. WHO Drug Information.Regulatory systems in India: An Important Global Hub for Medical Products and Technologies. Med. 2017;31:3.

20. Indian council for research on international economic relations"Drug Quality and Safety Issues in India Working Paper 310. 2020. Maulik Chokshi.Rahu Mongi.Vasudha Wattal. [cited Feb 2020]. Available from: https://icrier.org/pdf/ Working_Paper_310.pdf.

21. El-Jardali F, Akl EA, Fadlallah R, Oliver S, Saleh N, El-Bawab L, et al. Interventions to combat or prevent drug counterfeiting: A systematic review. BMJ Open. 2015:5(3):e006290

22. Infosys Serialization and the Drug Quality and Security Act. 2019. [cited Sep 2019]. Available from: https://www.pharmamanufacturing.com/articles/2015/ serialization-drug-quality-security-act/.

23. IFPMA. Serialization and Product Verification - Helping to Secure the Legal Supply Chain

24. for Greater Patient Safety. 2019. [cited Sep 2019]. Available from: https://www. ifpma.org/wp-content/uploads/2016/03/Joint-Industry-Position-Paper-on-Serialization-and-Product-Verification-.pdf.

25. Caudron JM, Ford N, Henkens M, Mace C, Kiddle-Monroe R, Pinel J, Substandard medicines in resource-poor settings: A problem that can no longer be ignored. Tropical Medicine and International Health: TM and IH. 2008;13( 8):1062-72.

26. Raufu A. India agrees to help Nigeria tackle the import of fake drugs. BMJ. 2003(326):74011234-.

27. Brechtelsbauer ED, Pennell B, Durham M, Hertig JB, Weber RJ. Review of the 2015 Drug Supply Chain Security Act. Hosp Pharm. 2016;51(6):493-500.

28. Kibet A, Bayyou DG, Esquivel R. Blockchain: It's structure, principles, applications and foreseen issues. 2019;6:4

29. Techracers. How Blockchain Contributes to Drug Supply-Chain Management. 2018. https://medium.com/techracers/how-blockchain-contributes-to-drug-supply-chain-management-8a1a67ac02ef.

30. Faisal JLH, Kyuhung K, DoHyeum K. A Novel Medical Blockchain Model for Drug Supply Chain Integrity Management in a Smart Hospital. MDPI Electronic 2019;8(5): 505

31. Blockchain Technology in Healthcare Market to Hit $\$ 1,636.7$ Mn by 2025: Global Market Insights, Inc. ." Blockchain Market. 2019

32. U.S. Food and drug administration Counterfeit Medicine. 2020. [cited 2020 March]. Available from: https://www.fda.gov/drugs/buying-using-medicine-safely/counterfeit-medicine.

33. Europena Medicine Agency. 2020. [cited March 2020]. Available from: https:// www.ema.europa.eu/en/human-regulatory/overview/public-health-threats/ falsified-medicines-overview.

34. Government of Canada. Policy on Counterfeit Health Products (POL-0048). 2020 https://www.canada.ca/en/health-canada/services/drugs-health-products/compliance-enforcement/activities/policy-counterfeit-health-products-0048.html.

35. CDSCO. Current Scenario of Spurious and Substandard Medicines in India. 2019. [cited Sep 2019]. Available from: https://cdsco.gov.in/opencms/opencms/ en/Home/.

36. Liang BA, Mackey TK. Sexual medicine: Online risks to health--the problem of counterfeit drugs. Nature Reviews Urology. 2012;9(9):480-2.

37. Blackstone EA, JrFuhr JP, Pociask S. The health and economic effects of counterfeit drugs. American Health and Drug Benefits. 2014;7(4):216-24.

38. Johnston A, Holt DW. Substandard drugs: A potential crisis for public health. $\mathrm{Br}$ J Clin Pharmacol. 2014;78(2):218-43.

39. Health Canada. A small number of bottles of the antibiotic Rofact@ (rifampin) may contain a different drug. 2009. http://www.healthycanadians.gc.ca/recallalert-rappel-avis/hc-sc/2009/13384a-eng.php.

40. Health Canada. Immediate recall by Mylan Pharmaceuticals: potential serious risk due to mislabelling of products. 2011. http://www.healthycanadians.gc.ca/ recall-alert-rappel-avis/hc-sc/2011/13584a-eng.php

41. Zee news. 60 medicines declared 'substandard' by drug regulator. 2017. https:// zeenews.india.com/health/60-medicines-declared-substandard-by-drug-regulator-check-out-the-entire-list-1998388

Article History: Submission Date : 19-05-2020; Revised Date : 21-06-2020; Acceptance Date : 22-07-2020

Cite this article: Mamtashanti M, Rahul J, Kashyap T. A Review On Regulatory Requirements To Prevent Counterfeit Drugs In India. Int. J. Pharm. Investigation, 2020;10(3):257-62 